\title{
Assessment of Knowledge, Attitude and Practice of Students Towards Sexual Transmitted Infection in Haile Mariam Mamo Preparatory School Debre Birhan, Ethiopia, 2013
}

\author{
Addis Adera ${ }^{1,}$ ", Mesfin Wudu', Yonas Yimam', Mulugeta Tamirie², Micias Aregah², Getenet Dessie ${ }^{2}$, \\ Fitwi Tinsae $^{3}$
}

${ }^{1}$ Department of nursing, Faculty of health sciences, Woldia University, Woldia, Ethiopia

${ }^{2}$ Department of Nursing, School of Health Science, Debre Birhan University, Debre Birhan, Ethiopia

${ }^{3}$ Department of Nursing, Dr. Tewelde Legesse Health Science College, Mekelle, Tigray, Ethiopia

Email address:

addisaderagebru@gmail.com (A. Adera)

\section{To cite this article:}

Addis Adera, Mesfin Wudu, Yonas Yimam, Mulugeta Tamirie, Micias Aregah, Getenet Dessie, Fitwi Tinsae. Assessment of Knowledge, Attitude and Practice of Students Towards Sexual Transmitted Infection in Haile Mariam Mamo Preparatory School Debre Birhan, Ethiopia, 2013. Science Journal of Public Health. Vol. 3, No. 4, 2015, pp. 563-571. doi: 10.11648/j.sjph.20150304.26

\begin{abstract}
Background- Sexually transmitted diseases are a major health problem affecting mostly young people, not only in developing, but also in developed countries. It is an infection that has a significant probability of transmission between humans by means of human sexual behavior, including vaginal intercourse, oral sex, and anal sex. Objectives: To assess the knowledge, attitude and practice on sexual transmitted infection among Haile Mariam Mamo preparatory school students, Debre Birhan, Ethiopia, 2013. Methods -An institutional based cross- sectional study was conducted from January 7 to June 15,2013 in Debre Birhan preparatory school, Northern Shoa Zone, Amhara Region, Ethiopia. A total of 347 students were involved in the study by using stratified random technique. Data were collected through Pre-tested questioner, the collected data were entered and analyzed using SPSS version 16 statistical package and manual techniques. P-value $<0.05$ was considered statistically significant. Result: Two hundred ninety (87\%) of respondents were in the age group of 15-19 years. Among the total participants regarding information heard sexual transmitted infection transmission and prevention method, fourteen (17.5\%) were from rural and two hundred forty six $(82.5 \%)$ were from urban. The most frequently media which could help the participants information about $\mathrm{r}$ Sexual transmission infection were radio/TV (76\%) followed by school (43.9\%), parent $(17.95 \%)$ and others (2.2\%).Most of the participants $242(77.6 \%)$ were considered sexual transmitted infection as a disease. However, 32910.35$)$ and $33(10.6 \%)$ of the participants were considered sexual transmitted infection as curse and syndromic respectively. Regarding treatment of sexual transmitted infection, the majority of the respondents $(61.8 \%)$ were treated at health institute followed by $(26.4 \%)$ were treated at home. Only(11.8\%) of participants were treated by religious based practice including traditional medicine. Conclusion: Even if most of the respondents have knowledge about STIs, till there are misconception and their practice remained quit low. Behavioral change communication and demonstration be done regularly as part of the routine service and through the out reach9 school Visit) program about optional prevention and control of sexual transmission infection practice to all students who came to health institute and outreach services especially preparatory school.
\end{abstract}

Keywords: Knowledge, Attitudes, Practice, HIV/AIDS \& STIs

\section{Introduction}

Sexually transmitted infection (STI)) are illnesses that have a significant probability of transmission from infected person to normal persons through sexual behavior, including vaginal intercourse, oral sex, and anal sex (1). STIs are found among people between 15 and 24 years; up to $60 \%$ of the new infections and half of all sero-positive people globally are in this age group $(2,3)$. In Indian society, it is seen that STIs are widely associated with social stigma, embarrassment and denial. Sexuality, and associated health risks are still a major taboo (4). Only $47 \%$ and $22 \%$ of the 
respondents knew that adults and infants respectively could contact STIs. Only 12\% felt they could contact STIs and 79\% felt that being faithful would prevent one from contacting STIs, $87 \%$ knew that STIs could be treated(5).There was no reduction of risky sexual behavior with increasing level of knowledge indicating that increasing level of knowledge does not necessarily reduce risky sexual behavior (6). Few studies also have reported prevalence and incidence rate of Sexual transmitted infection in Debre Birhan; the majority of the patients are above the age of 15(7). Sexually transmitted infections (STIs) are recognized as a major public health problem in most of the world. According to north America extrapolated statistics annual report of STI greater than 10 million in north America ,above 48 million in western Europe ,greater than 11 million in central Asia,7,881,783 in kenya,1,984,555 in Somalia, 6,306,495, in Uganda and $17,047,342$ in Ethiopia were infected in the year 2012/2013(8).In some parts of the developing world, over $90 \%$ of the population was infected with Sexual transmitted diseases. Despite long-standing control efforts, it is estimated that more than 500 million people still are at high risk of infection, over 140 million persons are infected and about 6 million are in Africa, the Middle East, Central and SouthEast Asia, and countries in Latin America(9). In 1996, more than 1 million people were being infected daily. About $60 \%$ of these infections occur in young people $<25$ years of age, and of these $30 \%$ were $<20$ years. Between the ages of 14 and 19 years old, STIs occur more frequently in girls than boys (2:1) respectively. This equalizes by age 20 . After three years of previous report (1999), an estimated 340 million new cases of Syphilis, Gonorrhea, and Chlamydia occurred throughout the world. . For instance, In Sub-Saharan Africa, the burden of new cases of Sexual transmitted infection were higher than other countries. In addition, the rate of $11 \%$ to $35 \%$ of all new cases of sexual transmitted infections in the country was curable.().. Ranking among the top five diseases for which adults in developing countries seek health care (10).In Ethiopia according to 2011 national review meeting report on STIs, a total of 451,686 cases of STIs were reported from all regions except SNNPR for the period 1998-2002 E.C. According to 2010 quarterly report 27,947 STI cases were reported from all regions (11). Although the epidemic is currently stable, HIV/AIDS remains a major development challenge for Ethiopia. The spread of HIV in any community is in part determined by the knowledge of attitude towards sexuality of its members and by their actual sexual practices 12). For instance, In North Shoa in the year 2011/2012, 1333 males and 2387 female STI patients were reported at OPD level. In spite of the high prevalence of STIs in Ethiopia, relatively little epidemiological research has been carried out ,the people with STIs who have minor or no symptoms do not seek treatment at public health facilities, lack of information on STIs ,health facilities offering treatment for STIs are far away from clients who present with STIs, Stigma associated with attending public STI clinics, and some patients do not attend formal STI clinics due to economic factors and they would rather go to traditional healers that provide services for free or with cheap costs, the prevalence of STI in Ethiopia is not well known(13). The knowledge of sexually transmitted diseases and sexual behaviors among Malaysian male youths that $92 \%$ of the respondents had heard of at least one of the listed STDs, which included syphilis, gonorrhea, Chlamydia, yeast infection, herpes, genital warts, trichomoniasis and HIV/AIDS. The disease that most people knew of was HIV/AIDS (90\%) and syphilis (59\%). The least known diseases were Chlamydia and trichomoniasis, only $13 \%$ of the respondents were aware of those diseases. When it came to STD transmission, $95 \%$ of the respondents knew at least one method (14). This custom provides women with opportunities for numerous transient sexual liaisons. Because of the limited employment opportunities available to women in Ethiopia, many select beer selling and prostitution as a way to earn an income. Thus, changes in the social structure, particularly in relation to the status of women, are contributing to the spread of STI. In general, neither health professionals nor the general population in Ethiopia understand the transmission process of STI, the serious nature of the problem, or how these diseases should be treated $(15,16)$. The finding of this study will help to know the knowledge, attitude and practice of adolescents towards STI and to determine what methods are more appropriate to educate adolescents about STI. The result of this investigation will also help the concerned bodies or sectors to know the problem in the study area and carry out their intervention activities for reduction of this problem. The main aim of this study was to assess the knowledge, attitude and practice on sexual transmitted infection among Haile Mariam Mamo preparatory school students, Debre Birhan, Ethiopia, 2013

\section{Methods and Materials}

\subsection{Study Area and Period}

This study was conducted in Debre Birhan preparatory school, Northern Shoa Zone, Amhara Region, Ethiopia. Located at a distance of $130 \mathrm{Km}$ North east of Addis Ababa, Amhara regional State, Ethiopia. The town is set up with 9 Keble with a total population of 94,829 .From this $50.9 \%$ are females. In the town there is only one preparatory school with a total number of 1715 students in which $47.7 \%$ are females. The study was conducted in randomly selected preparatory school students in Debre Birhan from January 18 - June 10, 2013.

\subsection{Study Design}

An Institutional based cross sectional study method was employed.

\subsection{Study Population}

Sampled students who are attending their education in Debre Birhan Preparatory school prior to the study. The Source population was all regular preparatory students 
registered in the academic year 2012/13 G.C. The study population was students in the preparatory school attending a day time education during year 2012/13 selected from the source of population with stratified sampling method from the students.

\subsection{Sample Size}

The sample size was determined by using a single population proportion formula considering the following assumption: Non proportion of preparatory students $16 \%(\mathrm{P}=0.16)(19)$., level of significance to be $5 \%(\mathrm{~d}=0.05)$ and design effect $=2$. By adding 105 non-response rate, the final sample size was 347 .

\subsection{Sampling Techniques}

First: Through obtaining students list from the school, students were stratified in two strata (grade 11, grade 12) based on grade level difference. Second: The total calculated sample was proportionally allocated to each grade based on the size of students. finally: respondent among each grade were selected by simple random sampling method by using table of random number using their ID number as frame of reference. Proportional allocation according to their size

$$
\begin{aligned}
& \text { Grade 11th }--\frac{842 \times 347}{1715}=170 \\
& \text { Grade12th }--\frac{873 \times 347}{1715}=177
\end{aligned}
$$

Then during data collection the selected students were assembled in to five different divided areas and then we administered the questioner and collect the required data.

\subsection{Instruments and Measurement}

Pretested and structured questionnaire was used. Questinnaires for each items are adapted from previously done similar studies (19). The instrument contains four parts: Sociodemographic characteristics of the respondents, Knowledge of students towards Sexual transmitted infection, attitudes and practice of the students towards sexual transmitted infection. The questionnaire was initially developed in English and translated in to Amharic by a person who has good ability of both language and then back to English to ensure consistence. The questioner was pretested in similar setting outside the study District (cha-cha preparatory school) with similar group as the target group.

\subsection{Data Collection Procedure}

Self administrated structured questionnaire which contain socio-demographic characteristics, knowledge, attitude and practice towards sexual transmitted infection was prepared to collect primary data. Questionnaire was pretested in 5\% preparatory students of the same grade in Debre Birhan having the same socio-demographic character before the actual data collection, data collectors and supervisors were appropriately trained for one day. One supervisor nursing professional personnel was involved in data collection. The questionnaire was initially developed in English and translated in to Amharic by a person who has good ability of both language and then back to English to ensure consistence. The questioner was pretested in similar setting outside the study District (cha-cha preparatory school) with similar group as the target group. Data was collected by five $4^{\text {th }}$ year nursing students. For both data collectors and supervisors one day training was given on data collection instruments, interview technique and importance of taking informed consent before data collection starts. Each day data was checked for completeness and consistency.

\subsection{Data Processing and Analysis}

The collected data was manually checked for completion for respondents are to be included in analysis and analysis was done manually. Frequencies, proportions and summary of descriptive statics were employed to describe the study population in relation to relevant variables. Odds ratio was used to assess the presence of association between independent and outcome variables. Test of significance was done using $\mathrm{X}^{2}$-test and a value of $\mathrm{p}<0.05$ were taken to indicate statistical significance.

\subsection{Data Quality Control}

Structured questionnaire was primarily prepared in English then translated to Amharic and then back to English by translator in order to look for consistency of the questions. After complete the correction pretest was done on cha-cha preparatory school and questionnaire was checked for completeness on daily basis. The completed questionnaires were also rechecked by the principal investigator to maintain the quality of data.

\subsection{Ethical Consideration}

Ethical clearance and approval was obtained from Institutional Review Board (IRB) DBU of school of health science. A formal letter from Debre Birhan University, School of Health science, was submitted to the school and, to all relevant offices and concerned bodies to obtain their cooperation. All study participants were informed about the purpose of the study and any additional information was given as they need, verbally and in written form. Efforts was done to overcome ethical concerns of the participants due to the sensitivity of the issue under study by careful designing and structuring the questionnaire; clear explanation about the purpose and usefulness of the study and by excluding names and other identifying numbers. The final report of the study was defended in Debre Birhan University, school of health science, department of nursing. Result of the study was disseminated to Haile Miriam Mamo preparatory school administrator, other relevant organizations working around sexual transmitted infection and individuals who need it to use as reference. 


\section{Result}

\subsection{Socio Demographic Characteristics}

A total of 333 respondents participated in this study making the response rate of $96 \%$. Among these respondents $165(49.5 \%)$ were males and $168(50.5 \%)$ were females. The age distribution of the respondents showed that most of the respondents (87\%) were between 15-19 years old. From respondents $291(87.4 \%)$ were followers of the Orthodox followed and others are other religion followers. Majority $253(76 \%)$ of the respondents were living in the town and 80 $(24 \%)$ of them are from rural area. Majority of $312(93.7 \%)$ of respondents were Amharas, and others comes from other regions. During the study period $236(70.9 \%)$ of the respondents were living with their family, 52(15.6\%) were living with rental house, and 45(13.5\%) were living with other relative house. From respondent's family 56(16.9\%) fathers and $89(26.7 \%)$ mothers are illiterate. One hundred and twenty (36\%) father\&109(32.7\%) mothers learn at primary school (1-8) level.

\subsection{Knowledge, Attitude and Practice of Stis}

Fourteen (17.5\%) rural and $246(82.5 \%)$ urban respondents ever heard about STI. Radio/TV was the most frequently information source for STI and others get information from other sources (fig-1). Regarding knowledge of respondents on sign \&symptoms of STI 233(74.7\%) of respondents know at least one sign \& symptoms of STIs but the rest $79(25.3 \%)$ didn't know any sign \& symptom of STI.
Table 1. Frequency Distribution on Socio-demographic characteristics of Preparatory students in Debre Birhan, 2013.

\begin{tabular}{|c|c|c|}
\hline Characteristics & Number & Percent \\
\hline \multicolumn{3}{|l|}{ Age } \\
\hline $15-19$ & 290 & 87 \\
\hline $20-25$ & 43 & 13 \\
\hline \multicolumn{3}{|l|}{ Ethnicity } \\
\hline Amhara & 312 & 93.7 \\
\hline Oromo & 12 & \\
\hline others & 9 & \\
\hline \multicolumn{3}{|l|}{ Religion } \\
\hline Orthodox & 291 & 87.4 \\
\hline Muslim & 19 & \\
\hline others & 23 & \\
\hline \multicolumn{3}{|c|}{ Father level of education } \\
\hline Illiterate & 56 & 16.9 \\
\hline $1-8$ & 120 & 36 \\
\hline $9-12$ & 85 & 25.5 \\
\hline$>12$ & 65 & 19.5 \\
\hline others & 7 & \\
\hline \multicolumn{3}{|c|}{ Mother level of education } \\
\hline Illiterate & 89 & 26.7 \\
\hline $1-8$ & 109 & 32.7 \\
\hline $9-12$ & 79 & 23.7 \\
\hline$>12$ & 56 & 16.9 \\
\hline \multicolumn{3}{|l|}{ Job of family } \\
\hline Farmer & 129 & 38.7 \\
\hline Merchant & 63 & 18.9 \\
\hline Gov’t employee & 111 & 33.4 \\
\hline Others & 30 & \\
\hline
\end{tabular}

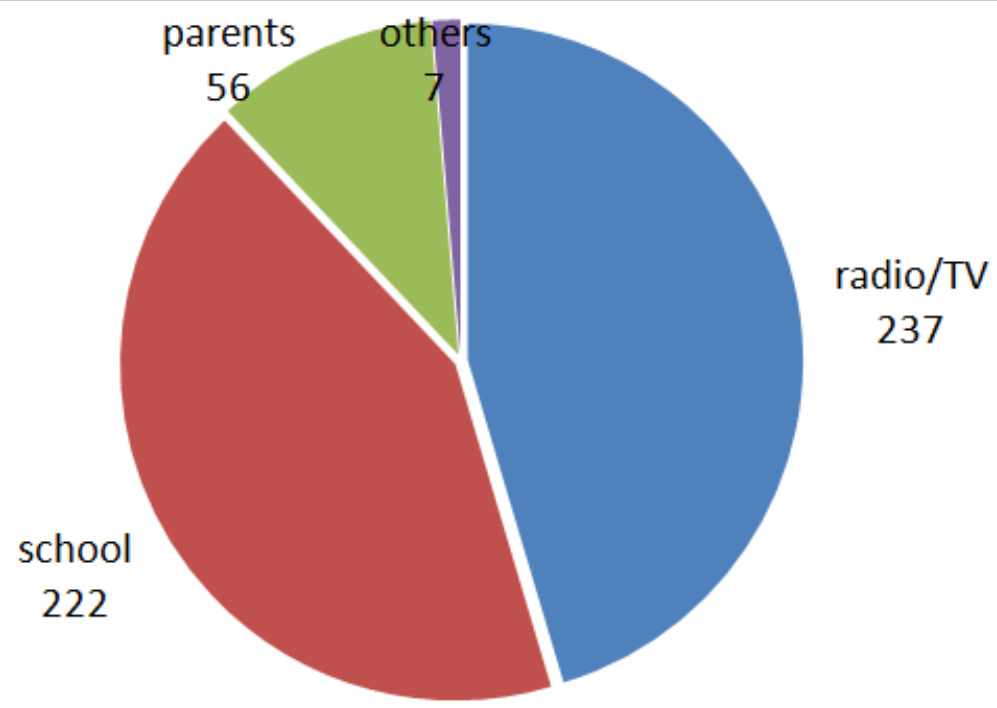

Figure 1. Frequency distribution of source of information for STIs among preparatory students in Debre Birhan, 2013.

Concerned with transmission of STI: $286(91.2 \%)$ of the respondents select individual transmission methods like sex $250(80.1 \%)$, blood contact 91(29.2\%), contaminated needle $58(18.6 \%)$, genetics 18 , breast feeding $33(10.6 \%)$ and the rest 9mentions other transmission methods in which more than one answer was possible. Regarding prevention method of STIs, majority of respondents 270(86.1\%) know prevention method of STI but $42(13.5 \%)$ of the respondents didn't know any prevention method of STI. 


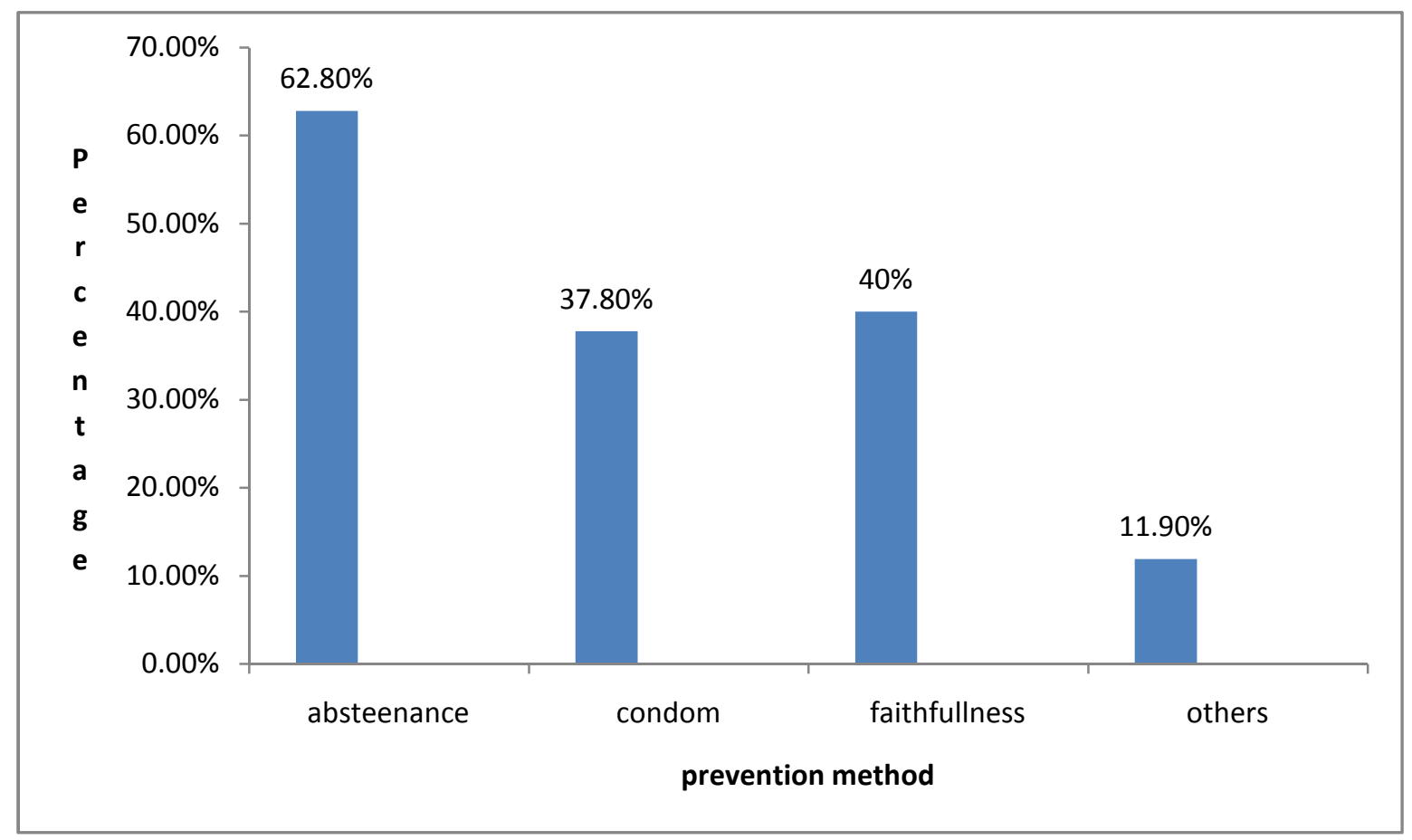

Figure 2. Percentage distribution of STIs prevention methods which were listed by respondents among preparatory students in Debre Birhan, 2013.

Table 2. Distribution of attitude among preparatory students on STIs in Debre Birhan, 2013.

\begin{tabular}{lll}
\hline Variable & No & Percentage (\%) \\
\hline $\begin{array}{l}\text { What do you think about STIs? } \\
\text { It is a diseases }\end{array}$ & 242 & 77.6 \\
Curse & 32 & 10.3 \\
Syndrome & 33 & 10.6 \\
$\begin{array}{l}\text { I don't know } \\
\text { What do you think about curability of STI? }\end{array}$ & 5 & \\
All are cured & 87 & 27.9 \\
There are cured and non cured & 182 & 58.3 \\
All are non cured & 31 & \\
I don't know & 12 & \\
$\begin{array}{l}\text { Do you think that STIs can transmit other } \\
\text { than sex? }\end{array}$ & & \\
Yes & 177 & 55.4 \\
no & 139 & 44.6 \\
$\begin{array}{l}\text { Do you think youths are vulnerable to STI? } \\
\text { Yes }\end{array}$ & 287 & 92 \\
no & 25 & \\
$\begin{array}{l}\text { Do you think that patients with STIs } \\
\text { should be isolated from the community? }\end{array}$ & & \\
yes & 87 & 27.9 \\
no & 225 & 72.1 \\
$\begin{array}{l}\text { Do you think patients with STIs are easily } \\
\text { identified in the community? }\end{array}$ & & \\
Yes & 104 & 33.3 \\
no & 208 & 66.7 \\
$\begin{array}{l}\text { Do you think that mosquito bite can } \\
\text { transmit STIs? }\end{array}$ & \\
$\begin{array}{l}\text { Yes } \\
\text { no }\end{array}$ & 103 & 33 \\
\hline
\end{tabular}

Two hundred forty- two (77.6\%) of respondents consider STI as a disease, where others consider STIs as course \&syndrome. From study participants who asked regarding curability of STI: $87(27.9 \%)$ names as curable, 182(58.3\%) says there are curable \&none curable, $31(9.93 \%)$ says all are none curable and the remaining 12 told that they didn't know anything about the curability of STIs. Among those respondents who consider STIs as curable and non curable, $47(25.8 \%)$ names the non curable STIs as curable. On perception of transmission 236(75.6) of the respondents believe that homo sexual intercourse can transmit STIs and $76(24.4 \%)$ didn't accept with this. From the participants $298(95.5 \%)$ of them consider STI as preventable but $14(4.5 \%)$ consider as non preventable diseases. The respondents also asked concerned with the impact of STIs; from these participants $181(58 \%)$ of them believes as it causes social isolation and stigma, but 131(42\%) didn't accept this idea.

Among respondents who participate in the study 34(10.9\%) have history of STIs .From those individuals who had history of STIs9 of them treated at home, $61.8 \%$ treated at health institution and the remaining 4 treated by other religious based practice. Among those individual who has treated at home $3 \%$ of them use animal product and the rest $6(66.7 \%)$ use herbal medication like leaves. From those individuals who perform sex $42(55.3 \%)$ didn't use condom, but the 34 $(44.7 \%)$ of them use condom. Among those who perform sex, $72(94.7 \%)$ perform sex at the age between 15-19, 3perform sex at the age greater than 19 , and 1perform sex at the age less than 13. Those students were also asked about factors that initiated them to perform sex, from those $29(38.2 \%)$ of them perform sex because of peer pressure, 29(38.2\%) perform sex because of age related increments of urge for sex, 12 perform sex for money and 6 of them perform sex because 
of other reasons. concerned with their plan for the future $130(39 \%)$ says abstinence, $160(48 \%)$ says faithfulness, and

$43(13 \%)$ says use condom.

Table 3. Distribution of practice among preparatory students on Sexual transmitted infections in Debre Birhan, 2013.

\begin{tabular}{lll}
\hline Variables & number & Percent \\
\hline Do you have history of STI? & 34 & 10.9 \\
Yes & 278 & 89.1 \\
No & 9 & \\
where you treated & 21 & 61.8 \\
home & 4 & \\
health institution & & \\
others & 160 & 51.3 \\
What measures you take for a person who is vulnerable to STIs? & 150 \\
Advice to abstaince & 160 \\
Advice to be faithful & 34 \\
Advice to use condom & 38 \\
Advice to wash his genitalia before sex & 51.3 \\
Advice to wash his genitalia after sex & 10.9 \\
\hline
\end{tabular}

*Excess number is due to response of more than one answer

Table 4. Determinant of the association between socio-demographic factors and knowledge of sign and symptom of STIs among preparatory students in Debre Birhan, 2013.

\begin{tabular}{|c|c|c|c|c|c|c|}
\hline Factors & Know sign and Symptom of STIs & & Total & $\mathbf{X}^{2}$ & COR & p-value \\
\hline Father level of education & & & & & & $<0.025$ \\
\hline$\geq 9$ & 124 & 20 & 144 & 7.03 & 1 & \\
\hline Illiterate & 22 & 28 & 50 & & 7.89 & \\
\hline Total & 233 & 79 & 312 & & & \\
\hline mother level of education & & & & & & $<0.025$ \\
\hline$<9$ & 74 & 28 & 102 & & 2.9 & \\
\hline Illiterate & 46 & 36 & 82 & & 5.9 & \\
\hline Total & 233 & 79 & 312 & & & \\
\hline \multicolumn{7}{|l|}{ Occupation of family } \\
\hline Gov't employee & 121 & 11 & 132 & 16.7 & 1 & \\
\hline Farmer & 62 & 56 & 118 & & 10 & $<0.005$ \\
\hline Total & 233 & 79 & 312 & & & \\
\hline
\end{tabular}

Table 5. Association between socio-demographic factors and knowledge of transmission method of STIs among preparatory students in Debre Birhan, 2013.

\begin{tabular}{|c|c|c|c|c|c|c|}
\hline \multirow[t]{2}{*}{ Variables } & \multicolumn{2}{|c|}{ Knowledge of transmission method } & \multirow[t]{2}{*}{ total } & \multirow[t]{2}{*}{$\mathbf{X}^{2}$} & \multirow[t]{2}{*}{ COR } & \multirow[t]{2}{*}{ p-value } \\
\hline & yes & no & & & & \\
\hline Father level of Education & & & & & & $<0.5$ \\
\hline$\geq 9$ & 132 & 12 & 144 & 0.65 & 1 & \\
\hline$<9$ & 112 & 6 & 118 & & 0.6 & \\
\hline Illiterate & 41 & 9 & 50 & & 2.4 & \\
\hline Total & 286 & 26 & 312 & & & \\
\hline \multicolumn{7}{|l|}{ Mother level of education } \\
\hline$\geq 9$ & 122 & 6 & 128 & 0.76 & 1 & $<0.5$ \\
\hline$<9$ & 95 & 7 & 102 & & 1.5 & \\
\hline Illiterate & 69 & 13 & 82 & & 3.8 & \\
\hline total & 286 & 26 & 312 & & & \\
\hline \multicolumn{7}{|l|}{ FAMILY OCCUPATION } \\
\hline Farmer & 96 & 14 & 110 & & 2.6 & $<0.75$ \\
\hline Merchant & 67 & 5 & 72 & & 1.4 & \\
\hline Total & 286 & 26 & 312 & & & \\
\hline
\end{tabular}


Table 6. Association of socio demographic characteristics and practice of condom use among preparatory students in Debre Birhan, 2013.

\begin{tabular}{lllllll}
\hline Variables & \multicolumn{2}{l}{ Use condom } & & $\mathbf{X}^{\mathbf{2}}$ & OR & P-value \\
\hline & Yes & no & total & & & \\
urban & 28 & 13 & 41 & 11.1 & 10.41 & $<0.005$ \\
rural & 6 & 29 & 35 & & & \\
Total & 34 & 42 & 76 & & & \\
$11^{\text {th }}$ & 11 & 18 & 29 & 0.48 & 0.6 & $<0.25$ \\
$12^{\text {th }}$ & 23 & 24 & 47 & & & \\
Total & 34 & 42 & 76 & & & \\
Male & 19 & 13 & 32 & 2.64 & 2.8 & \\
Female & 15 & 29 & 44 & & & \\
total & 34 & 42 & 76 & & & \\
\hline
\end{tabular}

\section{Discussion}

This study has tried to assess knowledge, attitude and practice of sexual transmitted infections among preparatory students in Debre Birhan town Amhara regional state. In this study $93.7 \%$ inwhich $17.5 \%$ rural and $82.5 \%$ urban respondents ever heard about STI. This result was lower than the previous studies conducted in Tanzania among in-school youths at which ages ranged from 13 to 25 years, however most of them (60\%) had age between 17 and 19 years, about $99 \%$ of the students have had heard about STIs(17). This may be because of some respondents in this study were from rural areas $(17.5 \%)$ have no access to mass media and Debre Birhan town also was not develop as capital city of Tanzania. But this result close with study conducted at age between 15 to 20 years in Palau Pinang, Malaysia, at which from respondents $10.6 \%$ claimed that they never heard about STIs (18).In this study the most frequently information source for STI were radio/TV (76\%) followed by school (43.9\%), parent $(17.95 \%)$ and others $(2.2 \%)$ in which multiple information source was common. The result is little bit different from survey done in Tanzania which revealed that majority of students $99 \%$ were capable of mentioning multiple sources of information about knowledge of STIs, and none of them mentioned parents or teachers as source of information. Also Radio and Television were cited by $93 \%$ of students as the source of information on STIs while the rest $45(7 \%)$ students had sought information on their own from internet and books $(p<0.001)(17)$. This may be due to development of the country civilization, they change the information delivery system to computerized one like internet, digital library. In this study $74.7 \%$ of respondents' aware sign\& symptoms of STIs but the rest $25.3 \%$ didn't know any sign \& symptom of STI. This is lower than a result that is conducted in Uganda Kampala, at which $90 \%$ of respondents mention two and above sign and symptoms of STIs (18). This variation may be due to Kampala is developed than our study area Debre Birhan in which different media and other information sources are not accessible as much as Kampala. But greater than study conducted in Tanzania, that most students had poor knowledge on the symptoms associated with STIs. Seventythree $11.5 \%$ female and $14.5 \%$ male students accurately described some symptoms associated with STIs. Two hundred and fifty-five $39 \%$ were completely unable to describe the symptoms compared with 165 (26\%) who were able to describe the STI-associated symptoms correctly $(\mathrm{p}<$ $0.001)[16]$.This difference may be due to currently in Ethiopia in order to improve health seeking behavior of patients with STI most Medias advert by calling sign and symptom of STIs. This investigation revealed that from those individuals who were interviewed with respect to the knowledge on other means through which STIs could be transmitted other than sexual intercourse, 55.7\% students responded positively while $139(44.6 \%)$ were unable to respond. Two hundred and eighty six $(91.7 \%)$ students said they were able to protect themselves from contracting STIs, $20(6.4 \%)$ said cannot protect themselves and 6(1.9\%) were response as they didn't know. This result is different from study which conducted in Tanzania in which, from 635 students who were interviewed with respect to the knowledge on other means through which STIs could be transmitted other than sexual intercourse, $77 \%$ students responded positively while $23 \%$ were unable to respond. Six hundred and thirteen (96\%) students said they were able to protect themselves from contracting STIs, $2.5 \%$ said cannot protect themselves and $1 \%$ were not sure (17). This may be in that area better education may be given about transmission of STIs. Concerned with their attitude towards risk of acquiring STIs most of the students $92 \%$ said they were at risk of contracting STIs, while $8 \%$ said as they are not at risk. This result is inconsistent with that of research conducted in Tanzania, $46 \%$ of the students said they were not at risk of contracting STIs, while $38 \%$ said they were at risk(17).This variation may be due to knowledge difference of respondents among the two study areas.

From study participants majority of respondents $86.1 \%$ calls prevention method of STI but $13.5 \%$ of the respondents didn't call any prevention method of STI. from prevention methods abstinence was listed by $62.8 \%$ of respondents ,followed by condom $37.8 \%$,feathifulness $40 \%$,avoid sex with commercial sex workers $14.1 \%$ \&avoid blood donate $8.7 \%$ in which more than one answer was common. This result is different from previous study which was Conducted in Durban, South Africa majority of the students mentioned condom $80.1 \%$ followed by zero gazing (46.4\%) and abstinence (19.9\%) (19).This different may be 
the effect of religious practice in this study area in which most religion institution oppose condom. There is also a little bit different from study done in Debre Markose regarding preventive knowledge of STI, respondents call individual preventive methods like abstinence $52.1 \%$ ), $70.0 \%$ said be faithful to one uninfected partner and $48.2 \%$ ccorrect and consistent condoms use (20).Concerned with local miss conception $33 \%$ of the study units of this study said mosquito bite can transmit sexual transmitted infection. This result is inconsistent with results of study done in Debre Markose for questions to common local misconceptions, $46 \%$ had at least one misconception $(20,21)$. This difference may be due to time difference at which today the perception of the community was changed from time to time due to education. In this study $27 . \%$ of them recommended to isolate patients with STIs from the community this is also have little bit similarity with that of study conducted in Gondar at which More than $30 \%$ of the students recommended isolation of AIDS patients $(22,23,24,25)$.Among respondents who had have history of STIs $(10.9 \%), 26.4 \%$ of them treated at home, $21(61.8 \%)$ treated at health institution and the remaining $4(11.8 \%)$ treated by other religious based practice. From those individuals who treated at home $3 \%$ of them use animal product and the rest $66.7 \%$ use herbal medication like leaves. This result is different from Study conducted at Hawassa, Ethiopia from sample students $59.63 \%$ of student had history of sexually transmitted infections and $40.37 \%$ had no history of STIs. From those students who had history STIs $49.88 \%$ was treated at home, $40.09 \%$ was treated at health institution and $10.03 \%$ ) was treated at other place. Out of those students who had history of STIs and treated at home, $52.45 \%$ was treated by animal product, $18.88 \%$ was treated by root $(16.08 \%)$ was treated by stem bark and $12.59 \%$ was treated by leaf $(17,26,27)$. This may be due to; currently health information was distribute by different media about STIs and its important of treated at health Institution. Fathers education of 9 and above classes had positive association with respondents knowledge of sign and symptoms of STIs $(\mathrm{COR}=2.58)$. Mothers education 9 and above classes had positive association with students knowledge of sign and symptoms of STIs $(\mathrm{COR}=2.9)$.Families occupation being a government employee had positive association with knowledge of sign and symptoms $(\mathrm{COR}=10)$. Residence of students being urban had positive association with condom usage $(\mathrm{COR}=10.4)$

\section{Strength and Weakness of This Study}

\subsection{Strength}

Even if confidentiality is a big issue in adolescent age response rate was interested.

\subsection{Weakness of This Study}

- Due to lack of resources different data quality assurance like SPSS and EPinfo were not used

- Because of the analysis was done manually it was difficult whether there is confounder factor or not.

- Self-reported information is subjected to reporting errors, missed values \&biases. Since the study touches sensitive issues the possibility of underestimation cannot be excluded.

Cross- sectional study design was used in the present study. This type of study design shows the exposure and outcome at the same point in time, so that we cannot formulate cause and effect relationship

\section{Conclusion}

Even if most of the respondents heard about STIs and know about STIs, till there are misconception and their practice remained quit low. Behavioral change communication and demonstration be done regularly as part of the routine service and through the out reach9school Visit) program about optional prevention and control of sexual transmission infection practice to all students who came to health institute and outreach services especially preparatory school. The main source of knowledge for respondents was radio/TV. Most of the respondents know the transmission and prevention method of STIs. There is association between father level of education, job of father\& job of mother with knowledge of sign and symptom of STIs. Priority should be given for reproductive health of youths, Anti STIs clubs in school should be strengthened and Programs concerning with STIs should focus on practice, since most of the respondents aware about STIs.

\section{Author's Contributions}

AA and MW have made substantial contributions to beginning and design, collection of data, analysis and interpretation of data and in drafting the manuscripts and correcting the comment given by the advisors.

$\mathrm{M} \mathrm{A}$ and MT, involved in revising the research paper and the manuscript critically for important intellectual context and approval of the final version to be published and participated in its design and coordination. He participated in the approval and funding process, participated in the design of the study participated in its design and coordination.YY, GD, FT have involved in revising the research paper and the manuscript critically for important intellectual context and approval of the final version to be published and participated in its design and coordination, had greater contribution in reviewing the manuscript English and topography. And helped to draft the manuscript.

\section{Acknowledgements}

We are thankful to all our department technical staffs for their excellent technical support. We are grateful to all the participants for their cooperation and Debre Birhan University for financial support for only completed this research. In addition, we would like to acknowledge for Journal whose helped us for free publication. 


\section{References}

[1] Http;//www.En.wikipidia.org/wiki. Sexual transmitted diseases, January 25, 2013.

[2] Dehne K.L., Riedner G.: Sexually Transmitted Infections among adolescents: The need for adequate health services, 2005, Page no. ixhttp://whqlibdoc.who.int/publications/2005/9241562889.pdf

[3] Hindin J., Hindin M.: Premarital Romantic PartnershipsAttitudes and Sexual Experiences of Youth in Delhi, IndiaInternational Perspectives on Sexual and Reproductive Health, 2009, 35 (2): 97-104

[4] Ruikar HA. Knowledge, Attitude and Practices about Sexually Transmitted Infections- A Study on Undergraduate College Students of Mumbai. Webmed Central Reproduction2013; 4(3):WMC004166

[5] Eze, UIH., B O., BO(2006). H. Knowledge, Attitude and Practice (KAP) of the Prevention of Sexually Transmitted Infections among Non Health Care Female Hospital Workers. NQJHM Vol. $16 \quad$ (4) 2006: pp. 132-137. http://dx.doi.org/10.4314/nqjhm.v16i4.12814

[6] Kunzang Norbu,K., Sontosh Mukhia,S., Tshokey( 2013). Assessment of knowledge on sexually transmitted infections and sexual risk behaviour in two rural districts of Bhutan . BMC Public Health, 13:1142: 2 - 6 . http://www.biomedcentral.com/1471-2458/13/1142

[7] North Shoa zonal health office 2011/12 annual STI report.

[8] http://www.rightdiagnosis.com/s/stds/statscountry.htm,feburary 19, 2013.

[9] Http://www.WHO.inf/vaccine-research/diseases shoa-sexual transmitted diseases/en/index/.htm/,February 01, 2013.

[10] Http://fhi.org/en/HIV AIDS/pub/archived/articles/AIDS captions/volum3no1, February 23, 2013.

[11] Federal Democratic Republic of Ethiopia, Ministry of Health (2005). Health and Health related Indicators 1995 E.C. Addis Ababa, February 2004.

[12] Shiferaw,Y., Alemu,A., Girma,A., Getahun,A., Kassa,A., Gashaw,A., Alemu,A.,Teklu,T., Gelaw,B(2011). Assessment of knowledge, attitude and risk behaviors towards HIV/AIDS and other sexual transmitted infection among preparatory students of Gondar town, North West Ethiopia. BMCResearchNotes, 4:505 http://www.biomedcentral.com/1756-0500/4/505

[13] Afsarah Manhood MA, Barney, N., Ali, S., Kadir, MM etal (2002).Community knowledge, attitude and practice regarding sexual transited infection in rural district of Pakistan Pac Med.Association.52 (1):21-24.

[14] Awang, H., Wong, LP., Jani, R. \& Low WY. (2013) Knowledge of sexually transmitted diseases and sexual behaviors among Malaysian male youths. Journal of Biosocial Science, 12:1-11

[15] Plordie, DS (1981). Sexual transmitted diseases in Ethiopia, social factor contributing to their spread and implications for developing countries.56 (6):357-362.

[16] Florence ,N., Zeeb,S.,Pallek,LS ., Zeeb,H(2011).Awareness and knowledge of sexual transmitted diseases among school going adolescents in Europe; systematic review of public literature .BMC Public Health.11:227.

[17] Kennedy, D., Mwambete,M., Matura,Z(2006). .Knowledge of sexually transmitted diseases among secondary school students in Dares Salaam, Tanzania. Afr Health Sci. 2006 September; 6(3): 165-169.

[18] Anwar, M., Syed, AS Sulaiman, Ahmadi, K., Khan, TM(2010) .Awareness of school students on sexually transmitted infections (STIs) and their sexual behavior: a cross-sectional study conducted in Pulau Pinang, Malaysia. BMC Public Health 10:571.

[19] Sekirime, WK., Tamale,J., Lule, JC., WabwireMangen,F(2001). Knowledge, attitude and practice about sexually transmitted diseases among University students in Kampala. Afar Health Sci. 2001 August; 1(1): 16-22.

[20] Melesse,DA (2010).Assessment of sexual risk perception and the determinants of protective behavior of stis/hiv/aids among female college students, in Debere-Markos town, Amhara regional state, Ethiopia, 2010.

[21] Alamrew, Z., Awoke, W., Fikadie, G., Shimekaw. B (2013). Prevalence and Correlates of Exchanging Sex for Money (Gift),among Private College Students in Bahir Dar City, Northwest Ethiopia. Clinical Medicine Research,2(6,):126134. doi: 10.11648/j.cmr.20130206.13

[22] Shiferaw,Y., Alemu,A., Girma,A., Getahun,A., Kassa,A., Gashawetal, A(2011).Assessment of knowledge, attitude and risk behaviors towards HIV/AIDS and other sexual transmitted infection among preparatory students of Gondar town, north west Ethiopia. BMC Research Notes 2011, 4:505.

[23] Huque and Muhammad(2011).. Sexual behavior and knowledge regarding STD among undergraduate students in Durban, South Africa. Sexual behavior and knowledge regarding STD.June 1, 2011.

[24] Yimer,M., Abera,B., Mulu,W., Belay Bezabih, B(2014). Knowledge, Attitude and Practices of High Risk Populations on Louse- Borne Relapsing Fever in Bahir Dar City, NorthWest Ethiopia. Science Journal of Public Health. 2( 1): 15-22. doi: $10.11648 /$ j.sjph.20140201.13

[25] Anteneh,ZA(2013). Prevalence and Correlates of Multiple Sexual Partnerships among Private College Students in Bahir Dar City, Northwest Ethiopia, Science Journal of Public Health.1(1): 9-17. doi: 10.11648/j.sjph.20130101.12

[26] Melesse, DA (2010). Assessment of sexual risk perception and the determinants of protective behavior of stis/hiv/aids among female college students, in Debere-Markos town, Amhara regional state, Ethiopia, 2010.

[27] Joseph O. Ogbe. Knowledge, Sources of Information and Practice of Condom Use in the Prevention of Sexually Transmitted Infections (STIs) among Rural Dwellers in Delta State, Nigeria. Ethno Med. 2011, 5(2): 107-114. 